\title{
Determination of Pyrethroidal Insecticides by Titration
}

\author{
Ritsuko Furuta, Hiroshi Nakazawa and Tadashi DoI \\ Environmental Health Science Laboratory, Sumitomo Chemical Co., Ltd., \\ 1-98, Kasugade Naka 3-chome, Konohana-ku, Osaka 554, Japan \\ Received October 1,1990
}

\begin{abstract}
Assays for typical pyrethroidal insecticides were developed to determine their absolute purity. Ressmethrin, furamethrin and phenothrin could be determined by a neutralizing titration after hydrolyzing with potassium hydroxide to achieve relative standard deviations (RSD) of $0.10,0.19$ and $0.35 \%$, respectively. Allethrin, phthalthrin and furamethrin could be determined by a neutralizing titration in a non-aqueous solvent after reacting with ethylenediamine to achieve RSD values of 0.10 , 0.14 and $0.09 \%$, and permethrin by a chlorine determination with the oxygen combustion method to achieve RSD of $\mathbf{0 . 2 3} \%$. These methods are effective for assays of the reference standards because there is no necessity for another reference standard.
\end{abstract}

Synthetic pyrethroids are widely used as agricultural and household insecticides owing to their high insecticidal activity and low mammalian toxicity. ${ }^{1)}$ It is important to control their quality at the time of manufacture for safe and effective use. For this purpose, various methods to determine the contents have been developed, among which, internal standard methods of gas chromatography (GC-IS) are mainly used because of their time-saving and accuracy. These GC methods are based on a comparison between the test sample and a reference standard, whose quality must be precisely verified for an accurate determination of the insecticide preparation. Consequently, it is necessary to develop so-called absolute assays such as titration, in which determination is carried out without the reference standards. However, there have been few reports about such assays, except for the determination of natural pyrethrins by the mercury reduction method $^{2)}$ or neutralizing titration $^{3)}$ after hydrolyzing the esters, and allethrin (PYN) by reacting with ethylenediamine (ED). ${ }^{4,5)}$ Therefore, we investigated absolute assays for the representative household pyrethroidal insecticides, PYN, phthalthrin (NPY), resmethrin (CHR), furamethrin (PYN·D), phenothrin (SUM) and permethrin (EXM) (Fig. 1), and established their value by using the

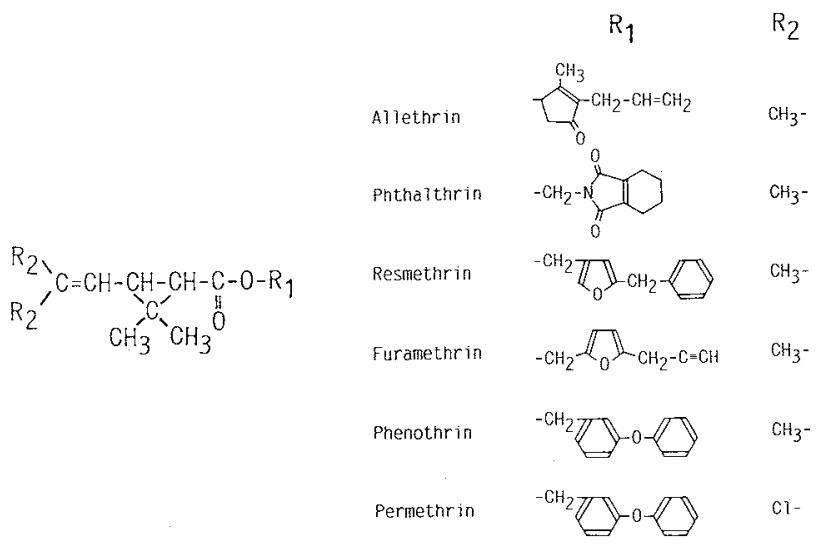

Fig. 1. Structures of Pyrethroidal Insecticides. 
neutralizing titration after hydrolyzing with potassium hydroxide $(\mathrm{KOH})$ or the reaction with $\mathrm{ED}$, or by the halogen determination with the oxygen flask combustion method.

\section{Materials and Methods}

Materials. Manufactured preparations of PYN, NPY, CHR, PYN.D, SUM and EXM were synthesized by Sumitomo Chemical Co., Ltd. (Osaka, Japan). Their reference standards were prepared by Sumitomo Chemical Co., Ltd. by independently recrystallizing manufactured preparations or by synthesis. ${ }^{6}$ The purity of each reference standard was $99.7-100.0 \%$ by the GC-peak area percentage method. Authentic samples of hydrolyzed products (chrysanthemic acid and 3-(2,2-dichlorovinyl)2,2-dimethylcyclopropane-1-carboxylic acid (DCPI)) were also synthesized by Sumitomo Chemical Co., Ltd.

Reagents. $2 \mathrm{~N}, 5 \mathrm{~N}$ and other $\mathrm{KOH}$ test solutions, $2 \mathrm{~N}$ and $5 \mathrm{~N}$ hydrochloric acid $(\mathrm{HCl}), 0.1 \mathrm{~N} \mathrm{KOH}$-ethanol $(\mathrm{EtOH})$, $0.1 \mathrm{~N}$ sodium methoxide-dioxane, thymolphthalein, and $0.01 \mathrm{~N}$ silver nitrate were prepared according to the Pharmacopoeia of Japan, General Tests, Processes and Apparatus. ${ }^{7)}$ Curcumin was prepared by dissolving $0.1 \mathrm{~g}$ of curcumin (analytical grade) in EtOH to make up $100 \mathrm{ml}$. ED (anhydrous, special class) was purchased from Kanto Chemical Co., Ltd. (Tokyo, Japan), all other reagents being of analytical grade.

Apparatus. A Shimadzu model GC-7A gas chromatograph equipped with a hydrogen flame-ionization detector, and a Hitachi model $\mathrm{M}-80 \mathrm{~B}$ mass spectrometer (electron impact ionization, $70 \mathrm{eV}$ ionization voltage, $180^{\circ} \mathrm{C}$ ion source) were used.

Neutralizing titration after hydrolyzing with $\mathrm{KOH}$ (method 1). About $0.3 \mathrm{~g}$ of CHR or SUM was accurately weighed, dissolved in $60 \mathrm{ml}$ of $\mathrm{EtOH}$, and $60 \mathrm{ml}$ of $2 \mathrm{~N}$ (for $\mathrm{CHR}$ ) or $5 \mathrm{~N}$ (for SUM) $\mathrm{KOH}$ was added to the solution. The mixture was refluxed for $2 \mathrm{hr}$ (for CHR) or $3 \mathrm{hr}$ (for SUM) and acidified (pH 3-4) with $2 \mathrm{~N}$ or $5 \mathrm{~N} \mathrm{HCl}$. After the solution had been cooled, $30 \mathrm{ml}$ of water saturated with sodium chloride was added. The reaction product was extracted with three $60-\mathrm{ml}$ portions of dichloromethane, the combined extracts were washed with two $120-\mathrm{ml}$ portions of water, and the dichloromethane was evaporated under reduced pressure. The residue was transferred to a conical flask with $50 \mathrm{ml}$ of EtOH and titrated with $0.1 \mathrm{~N} \mathrm{KOH-EtOH}$ (using 2-3 drops of curcumin as the indicator) until the color of the solution changed from yellow to red. A blank determination with $50 \mathrm{ml}$ of $\mathrm{EtOH}$ was performed in the same manner, and any necessary correction was made.
Neutralizing titration after reacting with ED (method 2). About $0.3 \mathrm{~g}$ of PYN, NPY or PYN $\cdot \mathrm{D}$ was accurately weighed into a glass-stoppered flask, dissolved in exactly $10 \mathrm{ml}$ of $\mathrm{ED}$ and allowed to stand at $50^{\circ} \mathrm{C}$ for $1 \mathrm{hr}$ (for PYN), at $25^{\circ} \mathrm{C}$ for $2 \mathrm{hr}$ (for NPY) or at $70^{\circ} \mathrm{C}$ for $3 \mathrm{hr}$ (for PYN.D). The stopper was then removed, the walls were washed with $50 \mathrm{ml}$ of pyridine, and the solution was titrated with $0.1 \mathrm{~N}$ sodium methoxide-dioxane (using $0.5 \mathrm{ml}$ of thymolphthalein as the indicator) until the color of the solution changed to blue (or from yellow to green with PYN - D). A blank determination was performed in the same manner, and any necessary correction was made.

Chlorine determination by the oxygen flask combustion method (method 3). About $0.01 \mathrm{~g}$ of EXM was accurately weighed, and the test was performed according to the Pharmacopoeia of Japan, Oxygen Flask Combustion Method, ${ }^{8)} 15 \mathrm{ml}$ of water being used as the absorbing liquid. $0.01 \mathrm{~N}$ silver nitrate was used as the titrant.

\section{Results and Discussion}

Neutralizing titration after hydrolyzing with KOH (method 1$)$

The effects of $\mathrm{KOH}$ concentration and reaction time on the hydrolysis were investigated. The resulting acids after hydrolyzing with $\mathrm{KOH}$ were extracted and titrated, the completion of the hydrolysis being determined by GC. ${ }^{9-12)}$ Figure 2 shows that the hydrolysis of CHR was completed in $2 \mathrm{hr}$ with $1 \mathrm{~N} \mathrm{KOH}$, in $1 \mathrm{hr}$ with $2 \mathrm{~N} \mathrm{KOH}$ and in $30 \mathrm{~min}$ with $4 \mathrm{~N}$ $\mathrm{KOH}$. The reaction for $2 \mathrm{hr}$ with $2 \mathrm{~N} \mathrm{KOH}$ was selected as the optimum. In a similar manner, the other pyrethroids were determined. Table I shows the optimum conditions and also the analytical results for the reference standards. This method was found to be applicable to CHR, PYN.D and SUM with RSD of $0.10-0.35 \%$. However, the contents of PYN

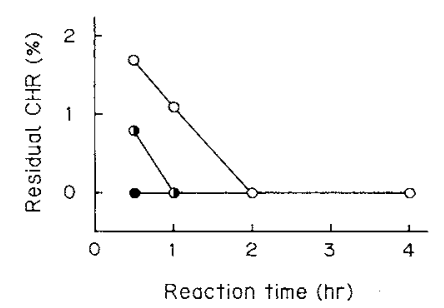

Fig. 2. Effect of $\mathrm{KOH}$ Concentration and Reaction Time on the Hydrolysis of CHR.

O, $1 \mathrm{~N}$ KOH TS;, 2 N KOH TS; $\bullet, 4 \mathrm{~N}$ KOH TS. 
Table I. Hydrolysis Conditions and Analytical Results For the ReFerence STandards of Pyrethrolds (Method 1)

\begin{tabular}{lccccc}
\hline Compound & $\begin{array}{c}\text { KOH TS } \\
(\mathrm{N})\end{array}$ & $\begin{array}{c}\text { Reaction } \\
\text { time } \\
(\mathrm{hr})\end{array}$ & $\begin{array}{c}\text { Content by } \\
\text { titration } \\
(\%)\end{array}$ & $\begin{array}{c}\mathrm{RSD}^{a} \\
(\%)\end{array}$ & $\begin{array}{c}\text { Content } \\
\text { by GC } \\
(\%)\end{array}$ \\
\hline PYN & 2 & 1 & 132.4 & - & 98.3 \\
NPY & 2 & 1 & 128.0 & - & 128.0 \\
CHR & 2 & 2 & 100.1 & 0.10 & 98.4 \\
PYN·D & 1 & 1 & 99.3 & 0.35 & 57.0 \\
SUM & 5 & 3 & 100.0 & 2.0 & 101.1 \\
EXM & 2 & 3 & 98.1 & 96.0 \\
\hline
\end{tabular}

a Relative standard deviation: PYN $\cdot \mathrm{D}, n=3$; others, $n=5$.

$b$ The extracted acids by method 1 were determined by GC-IS methods. The GC conditions were as follows. EXM: column, $3 \%$ Thermon $3000(3 \mathrm{~mm}$ i.d $\times 1 \mathrm{~m})$; column temp., $170^{\circ} \mathrm{C}$; internal standard, di-n-butyl phthalate Others: column, $5 \%$ FFAP ( $3 \mathrm{~mm}$ i.d. $\times 2 \mathrm{~m}$ ); column temp., $155^{\circ} \mathrm{C}$; internal standard, disopropyl phthalate.

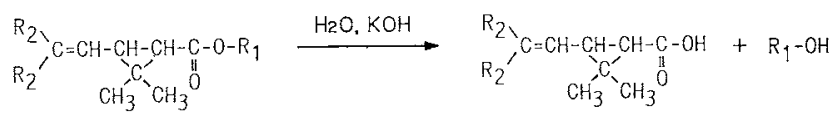

Fig. 3. Reaction Mechanism for Method 1.

$\mathrm{R}_{1}$, see Fig. I; $\mathrm{R}_{2}=\mathrm{CH}_{3}$, chrysanthemic acid; $\mathrm{R}_{2}=\mathrm{Cl}$, DCPI.

and NPY were overestimated. The reason is presumed to be that the alcohol moieties of PYN and NPY decomposed to acid products by a side reaction, which might have interfered with the titration. The hydrolysis products proved identical with an independently synthesized authentic sample of chrysanthemic acid or DCPI by judging from GC-mass spectral criteria (GC conditions are shown in Table I). The reaction mechanism is shown in Fig. 3.

To validate the results obtained by the titration method, the extracted acids by method 1 were determined by the GC-IS method under the conditions shown in Table I, authentic samples of the hydrolysis products being used as the reference standards. As shown in Table I, the analytical values for CHR and SUM were found to be the same as those by titration. However, that of PYN $\cdot \mathrm{D}$ was lower than that by titration, the reason for which is believed to be that there was a peak of an unknown product overlapping that of the internal standard. On the other hand, the content of NPY was overestimated, as was the case by titration, and overlapping of chrysanthemic acid and a by-product was observed on the gas chromatogram. The analytical value of PYN by $\mathrm{GC}$ shows that the hydrolysis conditions were valid, although the titration was unsuccessful as just described.

For EXM, method 1 was not applicable because the RSD was not acceptable.

\section{Neutralizing titration after reacting with ED (method 2)}

This method has been adopted as the determination method for PYN in AOAC. ${ }^{4)}$ We therefore tried to apply it to the other pyrethroids. In this method, each pyrethroid was reacted with $\mathrm{ED}$ (a milder reagent than $\mathrm{KOH}$ ) to form an equivalent acid, which was then titrated with sodium methoxide.

Figure 4 shows the effect of temperature on the reaction rate, the reaction proceeding more rapidly as the temperature increased, and being completed within $3 \mathrm{hr}$ at $70^{\circ} \mathrm{C}$ in the case of $\mathrm{PYN} \cdot \mathrm{D}$. The optimum conditions for the other pyrethroids were determined by the same procedure. Table II shows these optimum conditions and the analytical results for the reference standards. Although method 1 was not applicable to PYN and NPY, method 2 


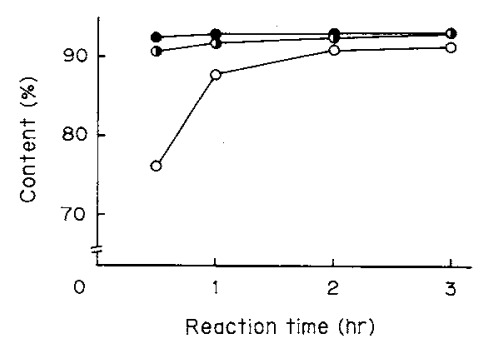

Fig. 4. Effect of Temperature on the Reaction Rate of PYN.D.

O, $50^{\circ} \mathrm{C} ; 60^{\circ} \mathrm{C} ; 70^{\circ} \mathrm{C}$.

Table II. Reaction Conditions and Analytical RESUlts FOR THE REFERENCE STANDARDS of Pyrethroids (MeThod 2)

\begin{tabular}{lcccc}
\hline Compound & $\begin{array}{c}\text { Reaction } \\
\text { temp. } \\
\left({ }^{\circ} \mathrm{C}\right)\end{array}$ & $\begin{array}{c}\text { Reaction } \\
\text { time } \\
(\mathrm{hr})\end{array}$ & $\begin{array}{c}\text { Content } \\
(\%)\end{array}$ & $\begin{array}{c}\mathrm{RSD}^{a} \\
(\%)\end{array}$ \\
\hline PYN & 50 & 1 & 99.9 & 0.10 \\
NPY & 25 & 2 & 99.8 & 0.14 \\
CHR & 70 & 1 & 1.5 & - \\
PYN $\cdot \mathrm{D}$ & 70 & 3 & 100.0 & 0.09 \\
SUM & 70 & 1 & 1.6 & - \\
EXM & 70 & 1 & 2.8 & - \\
\hline
\end{tabular}

a Relative standard deviation: $n=5$.

was applicable to these compounds and also to PYN D with $\mathrm{RSD}$ values of $0.09-0.14 \%$. It is considered that $\mathrm{KOH}$ is too strong as a reagent to break the ester bonds of PYN and NPY.

We also confirmed that the reaction product was identical with an independently synthesized authentic sample of chrysanthemic acid by judging from GC-mass spectral criteria (GC conditions are shown in Table I). Chrysanthemic acid produced by the reaction with ED was determined by the same GC-IS method as described in the foregoing section, although the analytical values varied, probably because of interference from excessive ED.

Owing to the low reactivity of CHR, SUM and EXM with ED, the analytical values were about $2 \%$ at $70^{\circ} \mathrm{C}$ for $1 \mathrm{hr}$, and therefore method 2 was not applicable to these compounds.

This method was simpler than method 1 because extraction was unnecessary.
Table III. EFfects Of THE Amount Of SAMPLE ANd ABSORBING LIQUid ON THE EXM CONTENT (Method 3)

\begin{tabular}{ccc}
\hline $\begin{array}{c}\text { Amount of } \\
\text { sample (mg) }\end{array}$ & $\begin{array}{c}\text { Absorbing } \\
\text { liquid }\end{array}$ & $\begin{array}{c}\text { EXM content } \\
(\%)\end{array}$ \\
\hline 100 & $10 \% \mathrm{H}_{2} \mathrm{O}_{2}$ & $99.5^{b}$ \\
50 & $10 \% \mathrm{H}_{2} \mathrm{O}_{2}$ & $99.9^{b}$ \\
50 & Water & $100.8^{b}$ \\
30 & $10 \% \mathrm{H}_{2} \mathrm{O}_{2}$ & $100.2^{c}$ \\
30 & Water $^{c}$ & $99.8^{c}$ \\
10 & $10 \% \mathrm{H}_{2} \mathrm{O}_{2}$ & $100.3^{c}$ \\
10 & Water & $100.5^{c}$ \\
\hline$a$ & Volume: $15 \mathrm{ml}$. & \\
$b$ & $0.05 \mathrm{~N}$ silver nitrate was used as the titrant. \\
$c$ & $0.01 \mathrm{~N}$ silver nitrate was used as the titrant.
\end{tabular}

Table IV. Analytical Results for Manufactured Preparations of Pyrethroids

\begin{tabular}{cccc}
\hline Compound & $\begin{array}{c}\text { Methods } \\
1-3 \\
(\%)\end{array}$ & $\begin{array}{c}\text { GC-IS } \\
\text { methods }^{12-15)} \\
(\%)\end{array}$ & $\begin{array}{c}\text { Difference } \\
(\%)\end{array}$ \\
\hline PYN & $96.5^{c}$ & 91.7 & 4.8 \\
NPY & $97.5^{c}$ & 95.0 & 2.5 \\
CHR & $94.8^{b}$ & 93.1 & 1.7 \\
PYN $\cdot D$ & $93.2^{c}$ & 91.1 & 2.1 \\
SUM & $96.6^{b}$ & 92.7 & 3.9 \\
EXM & $98.3^{d}$ & 92.5 & 5.8 \\
\hline
\end{tabular}

a $\quad$ Difference $=($ methods $1-3)-($ GC-IS methods $)$.

$b$ Method I was used.

c Method 2 was used.

d Method 3 was used.

Chlorine determination by the oxygen flask combustion method (method 3)

The oxygen flask combustion method is a general method for identifying or determining halogens or the sulfur produced by combusting organic compounds containing chlorine, bromine, iodine, fluorine or sulfur. ${ }^{8)}$ Permethrin (EXM), which contains chlorine, was determined by this method. The amount of the sample and the absorbing liquid had no effect on the content of EXM as shown in Table III. The conditions described in the Materials and Methods, that is, a $10 \mathrm{mg}$ sample and water as the absorbing liquid, were adopted for easy operation. The average content and the RSD of five determinations of the EXM reference 
standard by the adopted methods were $100.2 \%$ and $0.23 \%$, respectively.

\section{Determination of manufactured preparations}

We applied methods $1-3$ to manufactured preparations of the pyrethroids. Their contents, however, were overestimated by 2 to $6 \%$ in comparison with the contents by GC-IS methods $^{9-12)}$ (Table IV) owing to related substances which were present in the manufactured preparations and which reacted in addition to the active ingredients.

Although GC-IS methods were found to be more appropriate for determining the manufactured preparations than the titration methods from the foregoing results, these GC-IS methods require verified reference standards. Therefore, absolute assays for the reference standards established by titration are necessary, and they should be more effective by combining with purity tests such as the GC-peak area percentage in order to support GC-IS methods.

\section{References}

1) H. Yoshioka and J. Miyamoto, Kagaku to Seibutsu, 14, 549 (1976).

2) "Official Methods of Analysis," 14th Ed., ed. by S. Williams, AOAC, Arlington, VA, 1984, Sec. 6, 190 193.

3) "Sacchuzai Shishin," Nihon Yakugyo Shinbunsha, Tokyo, 1990 , p. 50

4) "Official Methods of Analysis," 14th Ed., ed. by S Williams, AOAC, Arlington, VA, 1984, Sec. 6, 165 170.

5) J. N. Hogsett, H. W. Kacy and J. B. Johnson, Anal. Chem., 25, 1207 (1953).

6) "Sacchuzai Shishin," Nihon Yakugyo Shinbunsha, Tokyo, 1990, pp. 8-30.

7) "The Pharmacopoeia of Japan," 11th Ed., The Society of Japanese Pharmacopoeia, Tokyo, 1987, pp. 147-260 (English version).

8) "The Pharmacopoeia of Japan," 11th Ed., The Society of Japanese Pharmacopoeia, Tokyo, 1987, pp. 91-94 (English version).

9) A. Murano, Agric. Biol. Chem., 36, 2203 (1972).

10) S. Sakaue, M. Kitajima, M. Horiba and S. Yamamoto, Agric. Biol. Chem., 45, 1135 (1981).

11) A. Murano, T. Doi and H. Kitahara, Agric. Biol. Chem., 36, 1277 (1972).

12) M. Horiba, A. Kobayashi and A. Murano, Agric. Biol. Chem., 41, 581 (1977). 